\title{
Skin and hair-on-a-chip: Hair and skin assembly versus native skin maintenance in a chip-based perfusion system
}

\author{
Ilka Wagner ${ }^{1 *}$, Beren Atac ${ }^{1}$, Gerd Lindner ${ }^{1}$, Reyk Horland ${ }^{1}$, Matthias Busek ${ }^{1}$, Frank Sonntag ${ }^{2}$, Udo Klotzbach$^{2}$, \\ Alexander Thomas ${ }^{1}$, Roland Lauster ${ }^{1}$, Uwe Marx ${ }^{1}$ \\ From 23rd European Society for Animal Cell Technology (ESACT) Meeting: Better Cells for Better Health \\ Lille, France. 23-26 June 2013
}

\section{Background and novelty}

In recent decades, substantial progress to mimic structures and complex functions of human skin in the form of skin equivalents has been achieved. Different approaches to generate functional skin models were made possible by the use of improved bioreactor technologies and advanced tissue engineering. Although various forms of skin models are successfully being used in clinical applications, in basic research, current systems still lack essential physiological properties for toxicity testing and compound screening (such as for the REACH program) and are not suitable for high-throughput processes.

\section{Experimental approach}

In particular, further bioengineering is necessary for the implementation of adipose tissue, hair follicles and a functional vascular network into these models. In addition, miniaturization, nutrient and oxygen supply, and online monitoring systems have to be implemented in sophisticated culture systems. To become one step closer to the in vivo situation, we produced microfollicles as in vitro hair equivalents and integrated them into skin models. These microfollicles containing skin tissues were cultured under static and dynamically perfused conditions and were compared to ex vivo scalp and foreskin skin organ cultures. Dynamic cultivation was performed in our Multi-Organ-Chip system (Figure $1 \mathrm{~A}$ ).

* Correspondence: ilka.wagner@tu-berlin.de

${ }^{1}$ Technische Universität Berlin - Berlin, Germany

Full list of author information is available at the end of the article

\section{Results and discussion}

The formation of functional neopapillae needs more than 48 hours. After the addition of keratinocytes and melanocytes, the self-organizing microorganoids follow a stringent pattern of follicular-like formation by generating polarized segments, sheath formations and the production of a hair shaft-like fiber. We show that the de novo formation of human microfollicles in vitro is accompanied by basic hair follicle like characteristics. The microfollicles can be used to study mesenchymalepithelial-neuroectodermal interactions and for the in vitro testing of hair growth-modulating substances and pigmentary effects. As the hair follicle is highly vascularized, it supports penetration of substances into the skin and further into the bloodstream. Testing of topically applied substances might therefore be performed with significantly enhanced validity by the incorporation of a microfollicle into a dynamic chip-based bioreactor containing a skin equivalent which mimics a physiological penetration route. Commercially available skin equivalent EpiDermFT were cultured in the Multi-OrganChip for 7 days with subcuteaneous tissue and showed better viability and comparable histological results to native skin (Figure $1 \mathrm{C}-\mathrm{J}$ ). Cellular and nutritional effect of the subcueaneous tissue is visible even under static conditions. Presence of subcuteaneous tissue decreased the expression of Tenascin $C$ in dermis which is a marker for inflamation and fibrosis. Integritiy of the epidermis and proliferating cells in epidermis kept prominently in combined tissues. Figure $1 \mathrm{~B}$ showes the staining of a skin equivalent with an successfully inserted microfollicle. 


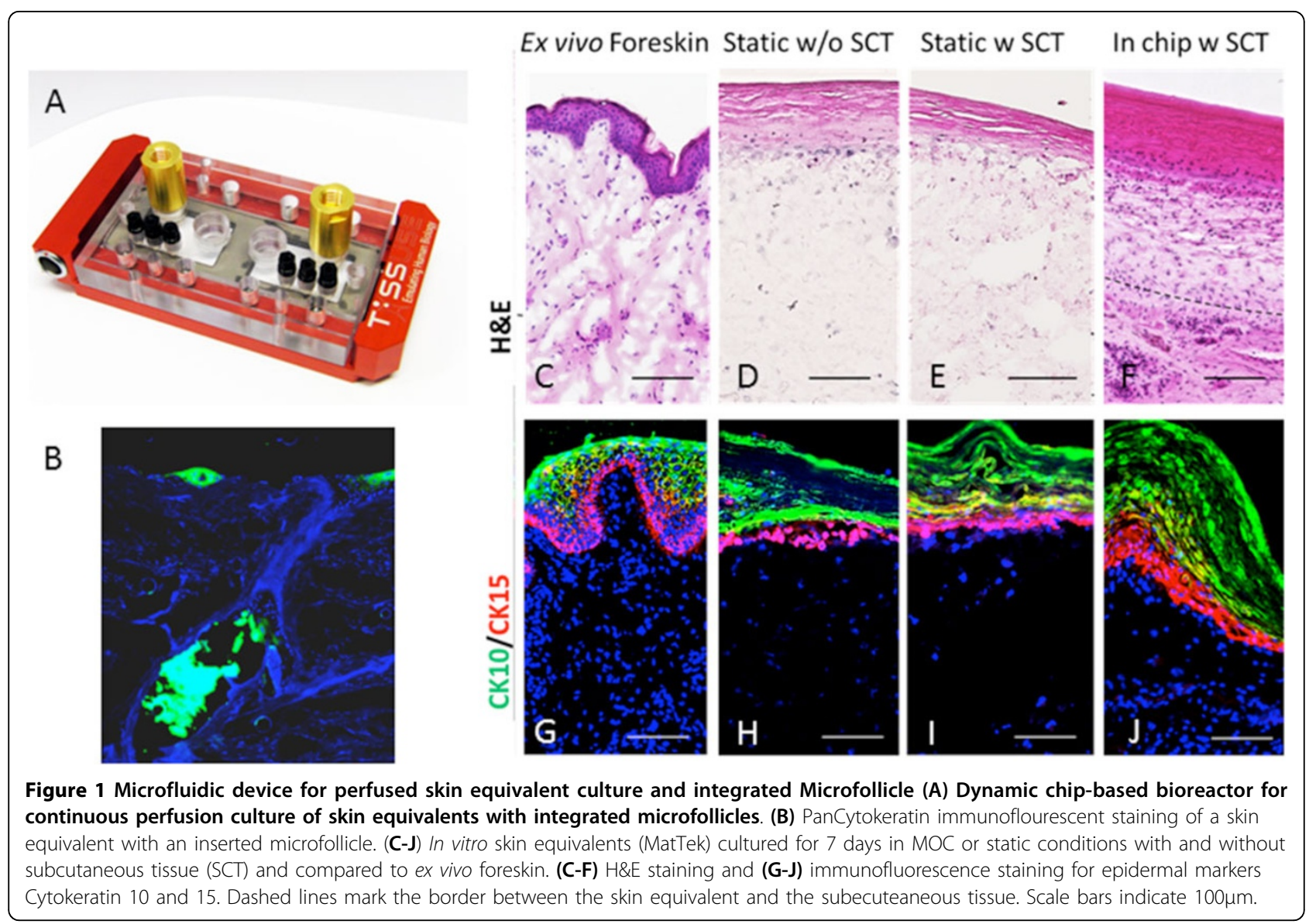

\section{Conclusion}

Perfusion of the combined tissue provides better integration and associated to viability of the subcuteaneous tissue. In general, presence of subcutaneous tissue increased the longevity of the in vitro skin equivalent in both static and especially in Multi-Organ-Chip cultures with improved tissue architecture. A skin equivalent with integrated microfollicles and subcutaneous tissue under dynamic perfusion will be the most suitable model for long-term cultivation and more efficient drug studies and one step closer to mimic in vivo skin.

\section{Acknowledgements}

The work has been funded by the German Federal Ministry for Education and Research, GO-Bio Grand No. 0315569.

\section{Authors' details}

${ }^{1}$ Technische Universität Berlin - Berlin, Germany. ${ }^{2}$ Fraunhofer IWS - Dresden, Germany.

Published: 4 December 2013

\section{doi:10.1186/1753-6561-7-S6-P93}

Cite this article as: Wagner et al:: Skin and hair-on-a-chip: Hair and skin assembly versus native skin maintenance in a chip-based perfusion system. BMC Proceedings 2013 7(Suppl 6):P93.

\section{Submit your next manuscript to BioMed Central} and take full advantage of:

- Convenient online submission

- Thorough peer review

- No space constraints or color figure charges

- Immediate publication on acceptance

- Inclusion in PubMed, CAS, Scopus and Google Scholar

- Research which is freely available for redistribution 